\section{AZOOSPERMIA FACTOR DELETIONS IN VARICOCELE CASES WITH SEVERE OLIGOZOOSPERMIA}

RIMA DADA, R. KUMAR ${ }^{\star}$, M. B. SHAMSI*, T. SIDHU*, A. MITRA***, S. SINGH ${ }^{\star}$, R. KUMAR ${ }^{\star \star}$, R. S. SHARMA ${ }^{\star \star *}$, S. K. GUPTA ${ }^{\star \star \star *}$, N. P. GUPTA ${ }^{\star *}$

\section{ABSTRACT}

BACKGROUND: Varicocele is the most common cause of male infertility. The etiology and pathophysiology of varicocele are multifactorial. When low sperm counts are associated with varicocele, varicocelectomy can partially restore spermatogenesis and fertility. Few recent studies have reported that in some varicocele cases, there may be an associated genetic etiology. Presence of a genetic factor like azoospermia factor microdeletions may lead to irreversible spermatogenic arrest in these cases, but very few reports support these findings. However, it is still not understood why some cases improve after varicocelectomy and why some cases show no improvement in semen parameters postoperatively. AIM: It is important to distinguish varicocele cases from $\mathrm{Yq}$ microdeletions as these cases have irreversible testicular damage and thus carry a poor prognosis after varicocelectomy. SEITINGS: Research and Referral tertiary care hospital. DESIGN: Prospective study. MATERIALS AND METHODS: Seventy-two infertile men with varicocele were referred for Yq microdeletion analysis from the infertility clinic of AllMS and Army Research and Referral Hospital. Genomic DNA was isolated from blood and polymerase chain reaction microdeletion screening was done in these cases to determine the presence or deletion of AZF loci. RESULTS: In this study 7 (9.7\%) varicocele cases harbored Yq microdeletion. The sperm count in cases which harbored Yq microdeletion was significantly lower than in cases without Yq microdeletion. CONCLUSION: Varicocele cases with $Y q$ microdeletion do not show improvement in semen parameters post-varicocelectomy. Detection of $\mathrm{Yq}$ microdeletion determines prognosis and future management in such cases.

Key words: ART, azoospermia factor microdeletions, infertility, varicocele C)

Laboratory for Molecular Reproduction and Genetics, Departments of *Anatomy and ${ }^{*}$ Urology, All India Institute of Medical Sciences, New Delhi, ***ART Centre, Army Research and Referral Hospital, AlIMS New Delhi, ${ }^{* * * *}$ Gamete Antigen Laboratory, NII, New Delhi, India

\section{Correspondence:}

Dr. Rima Dada

Laboratory for Molecular Reproduction and Genetics, Department of Anatomy, All India Institute of Medical Sciences, New Delhi - 110 029, India.
Varicocele is the pathological dilation of pampiniform plexus of veins. It is one of the leading causes of male infertility. The incidence of varicocele in the general population is about $15 \%$, while in infertile men the incidence is between 19 and $41 \% .^{[1,2]}$ In men with secondary infertility, the incidence is as high as $70-80 \% .{ }^{[1,2]}$ Thus varicocele is the most frequently identifiable and surgically correctable cause of male infertility. The etiology and pathophysiology of varicocele are multifactorial. When low sperm counts are associated with varicocele, varicocelectomy can partially restore spermatogenesis and fertility. ${ }^{[1,3-6]}$

There are several theories for the cause of varicocele; the most important is the difference in the drainage of right and left testicular vein. ${ }^{[7-9]}$

Increased venous and adrenal reflux affects testicular microvasculature by down-regulating the arterial inflow, and precapillary vasoconstriction affects nutrient supply to testis and also adversely affects mitochondrial oxidative phosphorylation. ${ }^{[10]}$ Varicocele adversely affects Leydig cell function, leading to decreased testosterone production and increased estrogen levels. ${ }^{[8,9,11]}$ Testosterone is required for optimal spermatogenesis, and reduced levels may lead to hypospermatogenesis. Elevated reactive oxygen species (ROS) and oxidative stress are found in $70-80 \%$ of men with varicocele. Though ROS are required for normal sperm physiological processes like signal transduction, sperm hyperactivation and capacitation, elevated ROS level causes lipid peroxidation of polyunsaturated fatty acids present in sperm head, leading to decreased motility, altered sperm morphology, enhanced apoptosis and impaired fertilization. ${ }^{[6,8,9]}$ Bacceti et al. ${ }^{[3]}$ reported that apoptosis, immaturity and necrosis were significantly higher in varicocele groups as compared to controls. Enciso et al..$^{[1]}$ reported maximum nuclear DNA damage in men with varicocele as compared to men with abnormal semen parameters due to other etiological factors. Marked improvement in sperm DNA integrity was found in men following varicocelectomy. ${ }^{[5,6]}$

Review of literature shows that there may be an underlying genetic etiology in varicocele and it may be the actual pathogenic factor leading to spermatogenic arrest in men with varicocele, but there are very few reports to support these findings. ${ }^{[12-15]}$ It is very important to distinguish varicocele cases from $\mathrm{Yq}$ microdeletions as these cases have irreversible testicular damage and thus carry a poor prognosis even afte varicocelectomy.

Azoospermia factor (AZF) loci on long arm of $Y$ chromosome contain genes or gene complex that is critical for germ cell development, differentiation and function. It consists of three non-overlapping loci (AZFa, AZFb and AZFc), each of which acts at a distinct stage of germ cell development. Deletion of each of the loci results in a characteristic phenotype. ${ }^{[16}$ Presently, there is much controversy about the mechanism of testicular damage in varicocele. Furthermore, it has not been clearly established if treatment is truly useful to restore testicula function. Therefore, this study was planned to understand if $\mathrm{Yq}$ microdeletions play a role in pathogenesis of spermatogenic arrest in varicocele cases. Presence of Yq microdeletion in cases with varicocele is an importan diagnostic and prognostic marker.

\section{MATERIALS AND METHODS}

Seventy-two infertile men with clinical varicocele and 25 age-matched fertile controls (who had fathered a child in the last one year) were included in this study. This study was carried out over a 9-year period from 1997 to 2006 . Each patient was carefully examined afte informed consent to rule out other causes of infertility; and a detailed medical, occupational, family and reproductive history was collected in each case. Only those cases were selected for study which had clinical varicocele. Semen 
samples were collected by masturbation after 5-7 days of abstinence and were examined in the same laboratory. The semen analysis was standardized according to World Health Organization (WHO) guidelines. ${ }^{[17]}$ Semen samples were analyzed twice, with an interval of 1 month between the two; and then after 6 months. The values of follicular stimulating hormone (FSH) levels were determined by radio immuno assay (RIA). Wherever possible, testicular cytopathological details following testicular fine needle aspiration cytology were collected as testicular biopsy was ethically not possible in these cases. Institutional ethical clearance was obtained prior to the study, and each patient was included in the study only after obtaining informed consent.

Polymerase chain reaction (PCR) analysis PCR screening was done for Yq microdeletions. Genomic DNA was isolated from blood by organic method. Each of these patients was examined for 6 AZF loci which were mapped to interval 5 and 6 of the long arm of $Y$ chromosome. The sequence-tagged site (STS) primers used were - for AZFa: sY84, sY86; for AZFb: sY127, sY134; for AZFc: sY254, sY255. The internal control used was SRY (Sex Determining Region on the short arm of $Y$ chromosome) -sY14. Fertile male and female samples were used as positive and negative controls, and water was used as blank. This primer set was suggested by Simoni et al. ${ }^{[18]}$ and prescribed by the European Academy of Andrology, and it enables the detection of over $90 \%$ of deletions in the AZF loci and allows for minimal standardization and comparison of the data on AZF deletions from different laboratories in different countries.

Samples were subjected to PCR amplification using 35 cycles of $95^{\circ} \mathrm{C}$ for $1 \mathrm{~min}, 56^{\circ} \mathrm{C}$ for 30 $\mathrm{s}$ and $72^{\circ} \mathrm{C}$ for $1 \mathrm{~min}$. Initial denaturation was done for $5 \mathrm{~min}$ at $95^{\circ} \mathrm{C}$, and final extension time of $7 \mathrm{~min}$ at $72^{\circ} \mathrm{C}$ was given.

The PCR products were analyzed on $1.8 \%$ 'agarose gel'-containing ethidium bromide $(0.5 \mu \mathrm{g} / \mathrm{ml})$. A STS was considered absent only after at least three amplification failures in the presence of successful amplification of internal control. In cases which were deleted for a particular AZF locus, the deletions were confirmed by lowering the annealing temperature and increasing the template DNA concentration.

\section{RESULTS}

Seventy-two men with clinical varicocele were included in this study. These cases were referred from the infertility clinic of All India Institute of Medical Sciences (AIIMS) and Army Research and Referral Hospital. Of these 72 cases, 64 cases had unilateral left-sided varicocele and 8 cases had bilateral varicocele; and 65 cases were oligozoospermic (mean sperm count $18 \pm$ $4.6 \mathrm{million} / \mathrm{ml}$ ) and 7 cases were azoospermic. All these cases had nonobstructive azoospermia (NOAZ) or oligozoospermia. Obstruction was ruled out clinically; and semen analysis was done twice, with an interval of 1 month between the two. The mean sperm count in control cases was $68 \pm 4.8 \mathrm{million} / \mathrm{ml}$. The sperm count in varicocele cases without $\mathrm{Yq}$ microdeletion was $19.6 \pm 4.7 \mathrm{million} / \mathrm{ml}$, and mean sperm count in cases which harbored $\mathrm{Yq}$ microdeletion was significantly lower $(7 \pm 2.1 \mathrm{million} / \mathrm{ml})$ as compared to cases without $\mathrm{Yq}$ microdeletion. The mean $\mathrm{FSH}$ value in varicocele cases was $32 \pm 2 \mathrm{miu} / \mathrm{ml}$ as compared to $5.2 \pm 1.2$ $\mathrm{miu} / \mathrm{ml}$ in controls. In varicocele cases with $\mathrm{Yq}$ microdeletion, the mean $\mathrm{FSH}$ value was $30 \pm 4.2$ $\mathrm{miu} / \mathrm{ml}$, which was not significantly different from that in varicocele cases without Yq microdeletion $(29 \pm 3.2 \mathrm{miu} / \mathrm{ml})$.

PCR amplification produced a band of expected size for all the seven loci investigated in the 65 varicocele cases and 25 fertile controls. ${ }^{[19]}$

Of the 72 cases with varicocele, 7 cases $(9.7 \%)$ harbored microdeletion of the AZF loci [Table 1]. Of these 7 cases, 6 cases had unilateral left-sided varicocele and 1 case had bilateral varicocele. All the cases that harbored microdeletion of AZF loci were azoospermic $(\mathrm{N}=4)$ or had severe oligozoospermia ( $\mathrm{N}$ $=3$ ) with sperm count of $7 \pm 2.1 \mathrm{million} / \mathrm{ml}$. Three cases harbored deletion of AZFc loci; 2 cases, AZFa loci; 1 case had deletion of $\mathrm{AZFa}+\mathrm{b}$ loci; and 1 case had deletion of $\mathrm{AZFb}+\mathrm{C}$ loci. FNAC data was available in 6 of the 7 cases with $\mathrm{Yq}$ microdeletion. In 2 cases with AZFa deletion and 1 case with $A Z F a+b$ deletion, there was complete absence of germ cells in the semeniferous tubules, characteristic of sertoli cell only type 1 (SCO Type 1) syndrome. Of the 3 cases with AZFC deletion, there was maturation arrest at the secondary spermatocyte stage in 1 case, hypospermatogenesis in the second case and the third case showed germ cells only in some semeniferous tubules - a picture characteristic of SCO Type 11 syndrome. Of these 72 cases, 30 cases underwent varicocelectomy but of these, only 9 cases came for follow-up examination and semen analysis. Of these cases, 5 cases harbored $\mathrm{Yq}$ microdeletion and 4 cases had no microdeletion. Semen analysis done 6 months postoperatively revealed that 5 cases with $\mathrm{Yq}$ microdeletion showed no improvement in semen parameters; in contrast, there was significant improvement in semen parameters in cases with no microdeletion.

\section{ISCUSSION}

Varicocele is the most common reversible cause of infertility. Although $15 \%$ of adult men have either clinical or subclinical varicocele its prevalence among infertile men is abou $40 \%{ }^{[6,12]}$ Few recent studies have reported that some varicocele cases harbor Yq microdeletions in the region critical for spermatogeneisis and spermiogenesis. ${ }^{[12-15]}$ Rao and associates ${ }^{[15]}$ reported that $24.56 \%$ cases of varicocele harbo genetic abnormalities, of which chromosomal

Table 1: Clinical phenotype of men with varicocele harboring azoospermia factor deletions

\begin{tabular}{|c|c|c|c|c|c|c|c|}
\hline$\overline{A g e}$ & Azoo/Oligo & $\begin{array}{c}\text { Semen } \\
(\times 106 \mathrm{ml})\end{array}$ & Varicocele & $F S H ~ m / U / m I$ & $\begin{array}{c}\text { Fine needle } \\
\text { aspiration cytology }\end{array}$ & $\begin{array}{l}\text { sequence-tagged } \\
\text { site Deleted" }\end{array}$ & $\begin{array}{c}\text { AZF } \\
\text { Deletion }\end{array}$ \\
\hline $\begin{array}{l}32 \\
24 \\
22\end{array}$ & $\begin{array}{l}\text { Azoo* } \\
\text { Azoo* } \\
\text { Azoo* }^{*}\end{array}$ & & $\begin{array}{c}\text { Unilateral (Left) } \\
\text { Unilateral (Left) } \\
\text { Bilateral }\end{array}$ & $\begin{array}{l}22 \\
60 \\
48\end{array}$ & $\begin{array}{l}\text { SCO Type } 1^{\ddagger} \\
\text { SCO Type } 1^{\ddagger} \\
\text { SCO Type } 1^{\ddagger}\end{array}$ & $\begin{array}{c}\text { sY84, sY86 } \\
\text { sY84, sY86, } \\
\text { sY84, } \\
\text { sY86, } \\
\text { sY127 } \\
\text { sY134 }\end{array}$ & $\begin{array}{c}\text { AZFa } \\
\text { AZFa } \\
\text { AZFa+AZFb }\end{array}$ \\
\hline 27 & Azoo* & & Unilateral (Left) & 34 & Not done & $\begin{array}{l}\text { sY127, } \\
\text { sY134, } \\
\text { sY254, } \\
\text { sY255 }\end{array}$ & $\mathrm{AZFb}+\mathrm{AZFC}$ \\
\hline 30 & oligo $^{\dagger}$ & 3 & Unilateral (Left) & 12 & Maturation arrest & $\begin{array}{l}\text { sY254, } \\
\text { sY255 }\end{array}$ & AZFc \\
\hline 33 & oligo $^{+}$ & 2 & Unilateral (Left) & 18 & Hypospermatogenesis & $\begin{array}{l}\text { sY254, } \\
\text { sY255 }\end{array}$ & AZFc \\
\hline 36 & oligo $^{+}$ & 4.2 & Unilateral (Left) & 21 & ScO Type $\|^{\S}$ & $\begin{array}{l}\text { sY254, } \\
\text { sY255 }\end{array}$ & AZFc \\
\hline
\end{tabular}


defects were observed in $19.3 \%$ cases and Yq microdeletions in $5.26 \%$ cases. Thus they postulated that there is a strong genetic association in varicocele cases. About 15\% azoospermic and 5-10\% oligozoospermic men harbor AZF microdeletions on long arm of $Y$ chromosome. ${ }^{[13,14]}$ However, these $Y$ chromosome microdeletions cannot be predicted cytogenetically or on the basis of clinical findings or semen analysis. Thus PCR-based $Y$ chromosome screening for microdeletions is necessary both for providing correct diagnosis, better management and counseling to infertile cases. ${ }^{[13,14,20,21]}$ This is highly relevant in the era of ART as majority of infertile couples, especially with severe male factor infertility, opt for assisted reproduction/ procreation techniques like intracytoplasmic sperm injection (ICSI). ${ }^{[20]}$

Varicocele due to nongenetic causes has a better prognosis with marked improvement of semen parameters and DNA integrity postoperatively. Such cases usually father a child 5-6 months after surgery. ${ }^{[1,3,6,9,10]}$ O'Brien et al. ${ }^{[4]}$ reported that adult varicocelectomy resulted in significant improvement in semen quality and pregnancy outcome. Following surgery, majority of varicocele cases show improvement in semen parameters, DNA integrity, testosterone levels and testicular volume. ${ }^{[1,2,3,5,9,10]}$ However, recent studies have reported that varicocele cases may harbor Yq microdeletions and such cases do not show any improvement in semen parameters postoperatively. ${ }^{[6,12]}$ Thus it is important to understand why some men with varicocele are fertile while others do not improve even after varicocelectomy.

In the present study, seven cases $(9.7 \%)$ with varicocele with severe testiculopathy had AZF microdeletions. It is possible that in these cases, the effect of high testicular temperature may only be additive to the effect of genetic abnormality and may have led to marked deterioration of testicular function and severe testiculopathy. It is also significant that Yq microdeletions were only present in cases with severe testiculopathy with azoospermia or severe oligozoospermia. Rao et al. ${ }^{[15]}$ proposed that there is strong association of genetic defects in infertile varicocele cases. However, though in our study $9.7 \%$ infertile varicocele cases harbored Yq microdeletion, larger studies are required to establish if there is a genetic association and whether genetic abnormalities are causally related to varicocele or this is just a coincidental finding because varicocele is the commonest cause of infertility.

(1)

Results of our preliminary study show that in these men, varicocele per se may not lead to spermatogenic arrest but its affect is only additive to the affect of AZF microdeletion. In such men, semen parameters do not improve even after surgical intervention. This has profound impact on male fertility. Such couples may opt for ART, and comprehensive counseling should be provided to such cases about iatrogenic transmission of the genetic anomaly and also of the chances of having secondary larger deletions as DNA damage is a promutagenic condition. ${ }^{[20,21]}$ Therefore, varicocele cases with severe oligozoospermia and azoospermia should undergo $\mathrm{Yq}$ microdeletion analysis as it is an important diagnostic and prognostic marker.

\section{ACKNOWLEDGEMENTS}

The authors are grateful to Indian Council of Medical Research and AlIMS for their financial support. Mr. Rakesh Kumar is SRF of ICMR.

\section{REFERENCES}

1. Enciso M, Muriel L, Fernandez JL, Goyanes V Segrelles $\mathrm{E}$, Marcos $\mathrm{M}$, et al. Infertile men with varicocele show a high relative proportion of sperm cells with intense nuclear damage level, evidenced by the sperm chromatin dispersion test. J Androl 2006;27:106-11.

2. Zucchi A, Mearini L, Mearini E, Costantini E, Bini V, Porena M. Treatment of varicocele: Randomized prospective study on open surgery versus Tauber antegrade sclerotherapy. J Andro 2005;26:328-32.

3. Baccetti BM, Bruni E, Capitani S, Collodel G, Mancini S, Piomboni $P$, et al. Studies on varicocele III: Ultrastructural sperm evaluation and $18, \mathrm{X}$ and $Y$ aneuploidies. J Androl 2006;27:94-101.

4. O’Brien JH, Bowles B, Kamal KM, Jarvi K, Zini A Microsurgical varicocelectomy for infertile couples with advanced female age: Natural history in the era of ART. J Androl 2004;25:939-43.

5. Pasqualotto FF, Sobreiro BP, Hallak J, Pasqualotto $\mathrm{EB}$, Lucon AM. Induction of spermatogenesis in azoospermic men after varicocelectomy repair An update. Fertil Steril 2006;85:635-9.

6. Zini A, Blumenfeld A, Libman J, Willis J. Beneficia effect of microsurgical varicocelectomy on human sperm DNA integrity. Hum Reprod 2005;20:101821.

7. Naughton CK, Nangia AK, Agarwal A Pathophysiology of varicoceles in male infertility. Hum Reprod Update 2001;7:473-81.

8. Agarwal A, Prbakaran S, Allameneni SS Relationship between oxidative stress, varicocele and infertility: A meta-analysis. Reprod Biomed Online 2006;12:630-3.

9. Agarwal A, Said TM, Bedawiy MA, Banerjee $\mathrm{J}$, Alvarez JG. Oxidative stress in an assisted reproductive techniques setting. Fertil Steri 2006:86:503-12.

10. Hsu. L, Goldstein M and Schlegel PN. The effects of varicocelectomy on serum testosterone levels in infertile men with varicoceles. J Uro 1995;154:1752-5.

11. Hudson RW. Free sex steroid and sex hormone- binding globulin levels in oligozoospermic men with varicoceles. Fertil Steril 1996;66:299-304.

12. Moro E, Marin P, Rossi A, Garolla A, Ferlin A. Y chromosome microdeletions in infertile men with varicocele. Mol and Cell Endocrinol 2000;161:6771.

13. Dada R, Gupta NP, Kucheria K. AZF microdeletions associated with idiopathic and non idiopathic cases with cryptorchidism and varicocele. Asian J Androl 2002;4:259-63.

14. Dada R, NP Gupta, K Kucheria. Cytogenetic and molecular analysis of male infertility: $Y$ chromosome deletion in nonobstructive azoospermia and severe oligozoospermia. Cell Biochem Biophysics 2006;44:171-7.

15. Rao L, Babu A, Kanakavalli M, Padmalatha V, Singh A, Singh PK, et al. Chromosomal abnormalities and y chromosome microdeletions in infertile men with varicocele and idiopathic infertility of South Indian origin. J Androl 2004;25:147-53.

16. Vogt $P H$, Edelmann $A$, Kirsch $S$, Henegariu $O$ Hirschmann $P$, Kiesewetter $F$, et al. Human $Y$ chromosome azoospermia factors (AZF) mapped to different subregions in Yq 11. Hum Mol Genet 1996;5:933-43

17. WHO Laboratory Manual for Examination of Human Semen and cervical mucus interaction. $3^{\text {rd }}$ ed. Cambridge University Press: Cambridge 1999.

18. Simoni M, Bakker E, Krausz C. EAA/EMQN best practice guidelines for molecular diagnosis of $Y$ chromosomal microdeletions. State of the art. In J Androl 2004;27:240-9.

19. Schoor RA, Elhanbly SM, Niederberger C. The pathophysiology of varicocele-associated male infertility. Curr Urol Rep 2001;2:432-6.

20. Kumar R, Dada R, Kiran Kucheria. Importance of genetic analysis prior to ICSI. Obstet Gynaeco Today 2006;11:461-3.

21. Dada R, Kumar R, Kumar R, Gupta NP, Kucheria K. Germ cell AZF deletion screening ideal prior to ART. Obstet Gynaecol Today 2006;11:7.

Source of Support: Nil, Conflict of Interest: None declared. 